\title{
Sean Morrison and the Texas brain gain
}

I n 2007, the Texas state constitution was amended to establish the Cancer Prevention and Research Institute of Texas (CPRIT). The new organization was endowed with $\$ 3$ billion to invest in cancer research in Texas over the next decade. The funds are intended to drive the recruitment of topnotch scientists to Texas institutions and fund innovative research programs. The JCI recently spoke to Sean Morrison, former Director of the Center for Stem Cell Biology at the University of Michigan, and now Director of the Children's Research Institute (CRI) at the University of Texas Southwestern Medical Center, about his own decision to move and about the development of Texas as a hub for biomedical research.

JCI: What made the move to Texas most appealing?

Morrison: I was really excited about the opportunity to launch a new research institute. The CRI will combine the clinical strengths of Children's Medical Center (Dallas) with the scientific strengths of UT Southwestern.

JCI: What makes the CRI unique?

Morrison: CRI will invest in potentially transformative - and hopefully translational - research in the areas of stem cell biology, cancer, and metabolism. I believe there are opportunities at the interfaces of these disciplines to open new fields and to discover new areas of biology. When this research yields opportunities to translate discoveries for the benefit of patients, CRI will dive deep to develop new therapies. $\mathrm{CRI}$ is unique because it is a joint venture between a world-class clinical institution, Children's Medical Center, and a worldclass scientific institution, UT Southwestern. It has the potential to recruit outstanding scientists because of the financial support of Children's Medical Center and CPRIT and the terrific facilities and environment at UT Southwestern.

JCI: As director, do you have a vision for what you hope will be accomplished there, a 5- or 10-year plan?

Morrison: The immediate goals are to recruit outstanding scientists, to perform groundbreaking research in the fields of stem cell biology and cancer, and to conduct research that illuminates the metabolic differences among different kinds of dividing somatic cells. The medium-term goal is to cultivate translational opportunities from this research that will improve the treatment of patients. The ultimate goal is to cure a patient who would not otherwise be cured.

JCI: What has been the most challenging adjustment?

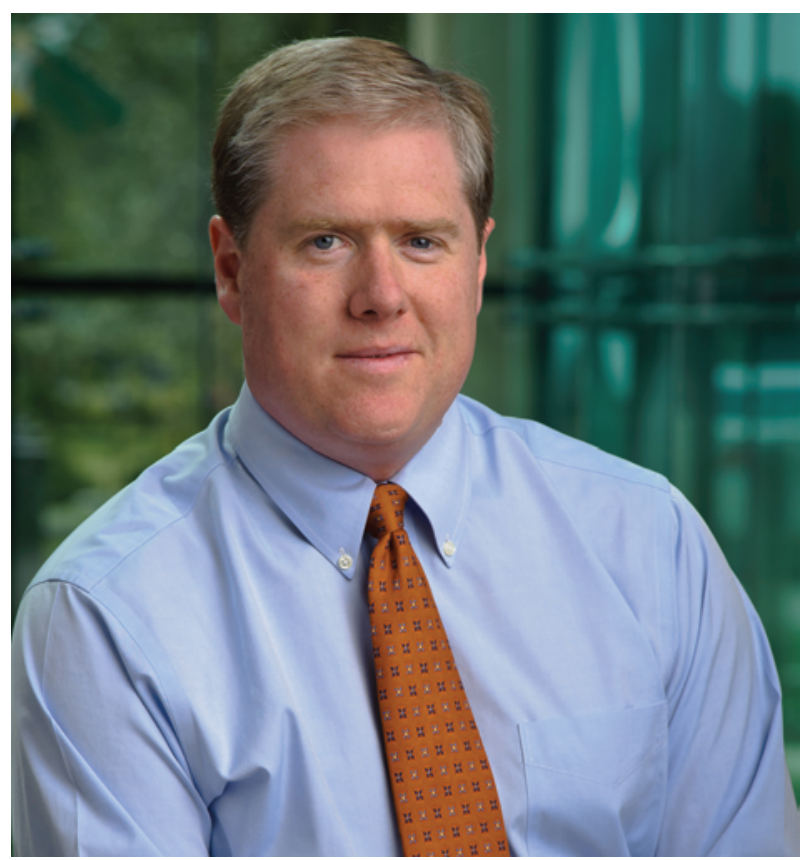

Morrison: There has been a tremendous amount of work to do: moving the laboratory, launching the new institute, and recruiting faculty to the institute. I was really surprised at how difficult it was to move an established laboratory. In addition, it was difficult to arrive in the new institute with no administrative staff in place. It's great to build something from scratch, but also a lot of work. I'm hoping it will get easier as I hire key people.

JCI: Were you able to bring most of your lab with you when you moved?

Morrison: Fortunately, yes. All of my students and postdocs who were not already on the job market moved with the lab to Dallas. Consequently, we haven't really had to go through a rebuilding phase.

JCI: The CPRIT has led a big push to recruit top-notch researchers to Texas. How do you think that has affected the research environment?

Morrison: A number of outstanding people have already moved to Texas, and a lot more are currently considering offers. Al Gilman, the Chief Scientific Officer, is doing an exceptional job of leading CPRIT, particularly though his investment in the recruitment of outstanding cancer biologists to the state. I believe that CPRIT will change the cancer research landscape in the United States. In a time of declining federal investment in biomedical research, the resources from CPRIT will make it possible to do things in Texas that are difficult or impossible to do in most other places.

JCI: Do you think Texas is on the way to being the world leader in biomedical research?

Morrison: It already is a world leader. It already has institutions like UT Southwestern, which is world-class in certain areas of biomedical research, and MD Anderson, which is world-class in certain areas of clinical research. I haven't done the math, but the density of Nobel laureates, HHMI Investigators, and National Academy Members at UT Southwestern may be higher than at any other medical school.

JCI: Will you miss the snow?

Morrison: Not even a little. This year I played golf on New Year's Eve for the first time.

Kathryn Claiborn 